EXTENDED REPORT

\title{
How to diagnose axial spondyloarthritis early
}

\author{
M Rudwaleit, D van der Heijde, M A Khan, J Braun, J Sieper
}

Ann Rheum Dis 2004;63:535-543. doi: 10.1136/ard.2003.011247

See end of article for authors' affiliations ....................

Correspondence to: Dr M Rudwaleit, Medizinische Klinik I, Charité-Campus Benjamin Franklin, Hindenburgdamm 30 , 12200 Berlin, Germany; martin.rudwaleit@ charite.de

Accepted 17 October 2003
Background: Chronic low back pain (LBP), the leading symptom of ankylosing spondylitis (AS) and undifferentiated axial spondyloarthritis $(\mathrm{SpA})$, precedes the development of radiographic sacroiliitis, sometimes by many years.

Objective: To assign disease probabilities and to develop an algorithm to help in the early diagnosis of axial SpA.

Methods: Axial SpA comprises AS and undifferentiated SpA with predominant axial involvement. Clinical features include inflammatory back pain (IBP), alternating buttock pain, enthesitis, arthritis, dactylitis, acute anterior uveitis, a positive family history, psoriasis, inflammatory bowel disease, and good response to NSAIDs. Associated laboratory findings include raised acute phase reactions, HLA-B27 association, and abnormalities on skeletal imaging. Sensitivities, specificities, and likelihood ratios (LRs) of these parameters were determined from published studies. A 5\% prevalence of axial SpA among patients with chronic LBP was used. The probability of the presence of axial SpA, depending on the presence or absence of the above clinical features of $\mathrm{SpA}$, was determined. A probability of $\geqslant 90 \%$ was used to make a diagnosis of axial SpA.

Results: The presence of inflammatory back pain features increased the probability of axial SpA from the background $5 \%$ prevalence to $14 \%$. The presence of 2-3 SpA features was necessary to increase the probability of axial SpA to $90 \%$. The highest LRs were obtained for HLA-B27 and MRI. Diagnostic algorithms to be used in daily practice were suggested.

Conclusions: This approach can help clinicians to diagnose with a high degree of confidence axial SpA at an early stage in patients with IBP who lack radiographic sacroilitis.
C hronic low back pain (LBP) is a common problem in general practice. ${ }^{1}$ The identification of treatable causes of back pain is therefore of great clinical relevance. Ankylosing spondylitis (AS) belongs to a group of related diseases termed spondyloarthritides (SpA), which also comprise diseases such as reactive arthritis, arthritis/spondylitis with inflammatory bowel disease, and arthritis/spondylitis with psoriasis, and also undifferentiated spondyloarthritis (uSpA). ${ }^{2}$ They share many clinical manifestations and the association with HLA-B27. The SpA as a group are one of the most common rheumatic diseases with a prevalence of $0.5-1.9 \%$, and this makes them at least as common as rheumatoid arthritis. The most common subgroups of SpA are AS and $\mathrm{uSpA}^{3-5}$ and all of them may progress to full-blown AS. Patients with inflammatory back pain (IBP) attributable to SpA are most likely to move on to AS and may develop a chronic disabling disease. The correct diagnosis of early disease has always been a challenge, which has become even more important because very effective new treatments have now become available. ${ }^{6-9}$

The established classification criteria for AS rely on the combination of clinical symptoms plus unequivocal radiographic sacroiliitis of at least grade 2 bilaterally or grade 3 unilaterally. ${ }^{10}$ The radiographs are often normal when first symptoms arise and it usually takes several years for definite radiographic sacroiliitis to evolve. Thus, the diagnosis of AS is commonly delayed by $8-11$ years after the onset of symptoms. ${ }^{11-13}$ As a result, diagnosing axial SpA (AS and uSpA with predominant axial involvement but without radiographic sacroiliitis) in the absence of radiographic sacroiliitis poses a major challenge to many physicians and rheumatologists. None the less, patients with axial SpA represent a spectrum of the same disease, and the presence or absence of radiographic (bony) changes is rather an indicator for severity or disease duration than for different disease entities. Attempts have been made in the past to classify SpA with predominant axial involvement before changes are detectable by radiography. ${ }^{14-20}$ At present, making the diagnosis of axial SpA at an early stage is difficult and highly dependent on clinical experience and intuition of the treating physician. The most often cited classification criteria for $\mathrm{SpA}$ are the European Spondylarthropathy Study Group (ESSG) criteria that were proposed in 1991. ${ }^{14}$ The introduction of uSpA as one SpA subtype for classification of patients with features characteristic for SpA but not fulfilling the criteria for one of the defined subtypes was a major step forward in the ESSG criteria. However, in a recent study from Spain the performance of the ESSG criteria as diagnostic criteria in daily practice was moderate: only $46.6 \%$ of patients with possible SpA who all met the ESSG criteria at entry into the study were judged by their rheumatologists to have SpA after 5 years of follow up..$^{19} 20$

We demonstrate that in patients with IBP but without radiographic sacroiliitis, an early diagnosis of axial SpA can be made with a high degree of confidence when at least two to three SpA features (clinical findings, laboratory tests, or skeletal imaging) are present. The decision trees proposed herein will help the physician in making an early diagnosis of axial SpA with greater confidence.

\section{METHODS}

The term "axial SpA" we use in this study includes AS and uSpA without radiographic sacroiliitis but with clinically

Abbreviations: AS, ankylosing spondylitis; CRP, C reactive protein; ESR, erythrocyte sedimentation rate; ESSG, European

Spondylarthropathy Study Group; IBP, inflammatory back pain; LBP, low back pain; LR, likelihood ratio; MRI, magnetic resonance imaging; NSAIDs, non-steroidal anti-inflammatory drugs; SpA, spondyloarthritis; uSpA, undifferentiated spondyloarthritis 
Table 1 Sensitivity, specificity, and positive likelihood ratios (LRs) of clinical and laboratory SpA features in patients with ankylosing spondylitis (AS), controls with back pain, patients with any spondyloarthritis, or any controls. Listing of references according to the year of publication

\begin{tabular}{|c|c|c|c|c|c|c|c|c|}
\hline & \multirow[b]{2}{*}{ Sens. (\%) } & \multirow[b]{2}{*}{ Spec. (\%) } & \multirow[b]{2}{*}{ Positive LR } & \multicolumn{4}{|c|}{ Group of patients and size of study group } & \multirow[b]{2}{*}{ Ref } \\
\hline & & & & AS (n) & $\begin{array}{l}\text { Back pain } \\
\text { controls (n) }\end{array}$ & All SpA (n) & Controls $(\mathbf{n})^{*}$ & \\
\hline Inflammatory back pain & $\begin{array}{l}95 \\
38 \\
65 \\
- \\
71 \\
75\end{array}$ & $\begin{array}{c}76 \\
100 \\
79 \\
75 \dagger \\
80 \\
76\end{array}$ & $\begin{array}{c}4.0 \\
\sim \\
3.1 \\
3.6 \\
3.1\end{array}$ & $\begin{array}{c}42 \\
21 \\
27 \\
101\end{array}$ & $\begin{array}{r}21 \\
422 \\
112\end{array}$ & & $\begin{array}{r}83 \\
774\end{array}$ & $\begin{array}{l}22 \\
10 \\
25 \\
24 \\
21\end{array}$ \\
\hline Alternating buttock pain & $\begin{array}{l}20 \\
39 \\
20 \\
43 \\
43 \\
32 \\
37 \\
40\end{array}$ & $\begin{array}{r}97 \\
98 \\
89 \\
95 \\
100 \\
97 \\
88 \\
90\end{array}$ & $\begin{array}{r}6.6 \\
19.5 \\
1.8 \\
9.6 \\
\sim \\
10.4 \\
3.7 \\
4.0\end{array}$ & $\begin{array}{r}44 \\
101\end{array}$ & $\begin{array}{r}29 \\
112\end{array}$ & $\begin{array}{l}403 \\
124 \\
104 \\
218 \\
105\end{array}$ & $\begin{array}{r}674 \\
1964 \\
75 \\
1242 \\
163\end{array}$ & $\begin{array}{l}14 \\
16 \\
27 \\
28 \\
30 \\
31 \\
21\end{array}$ \\
\hline Heel pain (enthesitis) & $\begin{array}{l}16 \\
37 \\
25 \\
52 \\
47 \\
50 \\
52 \\
37\end{array}$ & $\begin{array}{l}90 \\
89 \\
90 \\
92 \\
94 \\
96 \\
93 \\
89\end{array}$ & $\begin{array}{r}1.6 \\
3.4 \\
2.5 \\
6.5 \\
7.8 \\
12.5 \\
7.4 \\
3.4\end{array}$ & 70 & 29 & $\begin{array}{l}403 \\
104 \\
124 \\
218 \\
105\end{array}$ & $\begin{array}{r}674 \\
75 \\
1964 \\
1242 \\
163\end{array}$ & $\begin{array}{l}34 \\
14 \\
27 \\
16 \\
28 \\
30 \\
31\end{array}$ \\
\hline Peripheral arthritis & $\begin{array}{l}41 \\
40 \\
44 \\
42 \\
62 \\
26 \\
40\end{array}$ & $\begin{array}{r}94 \\
90 \\
95 \\
91 \\
100 \\
98 \\
90\end{array}$ & $\begin{array}{l}6.8 \\
4.0 \\
8.8 \\
4.7 \\
\sim \\
13 \\
\\
4.0\end{array}$ & 70 & 29 & $\begin{array}{l}403 \\
124 \\
218 \\
105\end{array}$ & $\begin{array}{r}674 \\
1964 \\
1242 \\
163\end{array}$ & $\begin{array}{l}34 \\
14 \\
16 \\
28 \\
30 \\
31\end{array}$ \\
\hline Dactylitis & $\begin{array}{l}18 \\
27 \\
24 \\
12 \\
18\end{array}$ & $\begin{array}{l}96 \\
99 \\
96 \\
98 \\
96\end{array}$ & $\begin{array}{c}4.5 \\
27 \\
6 \\
6 \\
4.5\end{array}$ & & & $\begin{array}{l}403 \\
124 \\
218 \\
105\end{array}$ & $\begin{array}{r}674 \\
1964 \\
1242 \\
163\end{array}$ & $\begin{array}{l}14 \\
16 \\
28 \\
31\end{array}$ \\
\hline Anterior uveitis & $\begin{array}{r}10 \\
19 \\
22 \\
14 \\
13 \\
4 \\
21 \\
22\end{array}$ & $\begin{array}{c}100 \\
- \\
97 \\
99 \\
99 \\
100 \\
- \\
97\end{array}$ & $\begin{array}{l}\sim \\
7.3 \\
14 \\
13 \\
\sim \\
7.3\end{array}$ & $\begin{array}{r}70 \\
42 \\
\\
676\end{array}$ & $\begin{array}{l}32 \\
12\end{array}$ & $\begin{array}{l}403 \\
124 \\
218 \\
105\end{array}$ & $\begin{array}{r}674 \\
1964 \\
1242 \\
163\end{array}$ & $\begin{array}{l}34 \\
12 \\
14 \\
16 \\
28 \\
31 \\
29\end{array}$ \\
\hline Psoriasis & $\begin{array}{l}17 \\
1.2 \\
10\end{array}$ & $\begin{array}{l}- \\
- \\
96 \ddagger\end{array}$ & 2.5 & $\begin{array}{l}807 \\
676\end{array}$ & & & & $\begin{array}{l}39 \\
29 \\
29\end{array}$ \\
\hline Inflammatory bowel disease & $\begin{array}{l}7 \\
1.7 \\
\mathbf{4}\end{array}$ & $\begin{array}{l}- \\
- \\
99 \ddagger\end{array}$ & 4 & $\begin{array}{l}828 \\
676\end{array}$ & & & & $\begin{array}{l}39 \\
29\end{array}$ \\
\hline $\begin{array}{l}\text { Positive family history for AS, } \\
\text { reactive arthritis, IBD, psoriasis, } \\
\text { anterior uveitis }\end{array}$ & $\begin{array}{r}7 \\
31 \\
32 \\
36 \\
20 \\
15 \\
10 \\
32\end{array}$ & $\begin{array}{r}100 \\
93 \\
95 \\
97 \\
100 \\
99 \\
-\quad 95\end{array}$ & $\begin{array}{l}\sim \\
4.4 \\
6.4 \\
12 \\
\sim \\
15 \\
\\
6.4\end{array}$ & $\begin{array}{r}70 \\
\\
44 \\
676\end{array}$ & $\begin{array}{l}32 \\
29\end{array}$ & $\begin{array}{l}104 \\
403 \\
218 \\
105\end{array}$ & $\begin{array}{r}75 \\
674 \\
1242 \\
163\end{array}$ & $\begin{array}{l}34 \\
27 \\
14 \\
28 \\
30 \\
31 \\
29\end{array}$ \\
\hline Response to NSAIDs & $\begin{array}{l}77 \\
71 \\
61 \\
64 \\
77\end{array}$ & $\begin{array}{r}85 \\
75 \\
80 \\
-\quad \\
85\end{array}$ & $\begin{array}{l}5.1 \\
2.8 \\
3.1 \\
\\
5.1\end{array}$ & $\begin{array}{r}69 \\
676\end{array}$ & 769 & $\begin{array}{l}218 \\
105\end{array}$ & $\begin{array}{r}1242 \\
163\end{array}$ & $\begin{array}{l}16 \\
28 \\
31 \\
29\end{array}$ \\
\hline
\end{tabular}




\begin{tabular}{|c|c|c|c|c|c|c|c|c|}
\hline & \multirow[b]{2}{*}{ Sens. (\%) } & \multirow[b]{2}{*}{ Spec. $(\%)$} & \multirow[b]{2}{*}{ Positive LR } & \multicolumn{4}{|c|}{ Group of patients and size of study group } & \multirow[b]{2}{*}{ Ref. } \\
\hline & & & & AS (n) & $\begin{array}{l}\text { Back pain } \\
\text { controls }(\mathrm{n})\end{array}$ & All SpA (n) & Controls $(\mathbf{n})^{*}$ & \\
\hline \multirow{8}{*}{$\begin{array}{l}\text { Raised acute phase reactants } \\
\text { (CRP) }\end{array}$} & 49 & 100 & $\sim$ & 70 & 32 & & & 34 \\
\hline & 69 & 67 & 3 & 42 & 12 & & & 12 \\
\hline & 39 & - & & 443 & & & & 35 \\
\hline & 38 & - & & 149 & & & & 36 \\
\hline & 75 & - & & 70 & & & & 7 \\
\hline & 51 & 75 & 2 & 101 & 112 & & & 21 \\
\hline & $56 \S$ & - & & & & & & \\
\hline & 50 & 80 & 2.5 & & & & & \\
\hline \multirow[t]{7}{*}{ HLA-B27 } & 96 & 96 & 24 & 40 & & & 906 & 37 \\
\hline & 88 & 92 & 11 & 75 & & & 75 & 38 \\
\hline & 83 & 95 & 16.6 & 70 & 32 & & & 34 \\
\hline & 88 & - & & 42 & 12 & & & 12 \\
\hline & - & 91 & & & & & 1871 & 3 \\
\hline & 89 & 94 & 14.8 & 101 & 112 & & & 21 \\
\hline & 90 & 90 & 9.0 & & & & & \\
\hline \multirow[t]{6}{*}{$M R^{\star \star *}$} & 93 & 100 & $\sim$ & 25 & 12 & 15 & & 40 \\
\hline & 54 & 83 & 3.1 & & 12 & 24 & & 41 \\
\hline & 83 & 93 & 11.8 & 36 & 53 & 36 & & 42 \\
\hline & 94 & 100 & $\sim$ & & 20 & 17 & & 43 \\
\hline & 90 & - & & & & 41 & & 44 \\
\hline & 90 & 90 & 9.0 & & & & & \\
\hline
\end{tabular}

Figures in bold indicate the sensitivities, specificities, and positive LRs taken in our calculations.

*Controls were in general patients with musculoskeletal diseases other than SpA; †apparently healthy sportsmen who had had an episode of back pain; †data on control patients were not available. Thus, the prevalence in the general population was assumed; $\S d$ ata from a German observational study on $\mathrm{SpA}$ ( $\mathrm{AS} \mathrm{n}=138$, unpublished); " sensitivity of HLA-B27 refers to SpA with axial involvement-that is, with inflammatory back pain; ${ }^{* *} M R I$ denotes magnetic resonance imaging.

predominant axial involvement. Clinical SpA features of axial SpA include IBP, alternating buttock pain, enthesitis, arthritis, dactylitis, acute anterior uveitis, a positive family history, and a good response to non-steroidal anti-inflammatory drugs (NSAIDs). Associated laboratory findings include raised acute phase reactants, HLA-B27 association, and abnormalities on skeletal imaging. The sensitivities, specificities, and positive likelihood ratios (LRs) of all these SpA parameters were extracted from published studies. ${ }^{10} 121421-44$ Table 1 presents the size of the study groups and type of patients (AS or SpA) and controls (healthy controls or patients with musculoskeletal diseases other than $\mathrm{SpA}$ ) of each of the studies, together with figures for sensitivity and specificity of each SpA parameter. As can be seen in table 1, the figures for sensitivity and specificity of individual SpA features were preferentially selected, if possible, from patients with AS (in contrast with the whole group of $\mathrm{SpA}$ ) and from back pain controls (in contrast with healthy controls or patients with diseases other than SpA). In studies where the distinction between AS and SpA, and back pain controls and other controls, respectively, was not made we had to take figures for the whole group of SpA and controls (table 1). We then estimated an average figure for sensitivity and specificity for each parameter which appeared to be representative to be used in our calculations ( shown in bold letters in table 1). In general, we decided on rather conservative estimates in order not to overestimate either sensitivity or specificity of an individual SpA feature.

Scintigraphy of the sacroiliac joints can be helpful if unilateral sacroiliitis is present but, in general, scintigraphy

Table 2 Selection of possible combinations of features in patients with low back pain presenting to primary care. The pretest probability refers to the prevalence of axial spondyloarthritis $(\mathrm{SpA})$ among patients with chronic back pain, the post-test probabilities result from the presence $(+)$ or absence $(-)$ of various SpA features

\begin{tabular}{|c|c|c|c|c|c|}
\hline \multicolumn{5}{|c|}{ Pretest prob. (\%)Possible combination of clinical, laboratory, or imaging SpA features } & \multirow{2}{*}{$\begin{array}{l}\text { Post-test prob. (\%) } \\
51\end{array}$} \\
\hline 5 & IBP (+) plus & Family history (+) & & & \\
\hline 5 & IBP $(+)$ plus & Heel pain $(+)$ & & & 35 \\
\hline 5 & $\mathrm{IBP}(+)$ plus & Uveitis (+) & & & 54 \\
\hline 5 & IBP $(+)$ plus & Synovitis (+) & & & 39 \\
\hline 5 & IBP $(+)$ plus & Dactylitis (+) & & & 42 \\
\hline 5 & IBP $(+)$ plus & Family history $(+)$ plus & Heel pain $(+)$ & & 78 \\
\hline 5 & $\mathrm{IBP}(+)$ plus & Uveitis (+) plus & NSAID $(+)$ & & 85 \\
\hline 5 & IBP $(+)$ plus & Heel pain $(+)$ plus & Synovitis (+) plus & Alternating buttock pain (+) & 89 \\
\hline 5 & $\mathrm{IBP}(+)$ plus & Family history $(+)$ plus & Heel pain $(+)$ plus & NSAID $(+)$ & 95 \\
\hline 5 & IBP $(+)$ plus & Heel pain $(+)$ plus & HLA-B27 $(+)$ & & 83 \\
\hline 5 & IBP $(+)$ plus & NSAIDs (+) plus & HLA-B27 (+) & & 88 \\
\hline 5 & IBP $(+)$ plus & Heel pain $(+)$ plus & HLA-B27 (-) & & 6 \\
\hline 5 & $\mathrm{IBP}(+)$ plus & NSAID (+) plus & HLA-B27 (-) & & 8 \\
\hline 5 & IBP $(+)$ plus & Dactylitis (+) & ESR/CRP (+) & & 62 \\
\hline 5 & $\mathrm{IBP}(+)$ plus & HLA-B27 (+) plus & ESR/CRP (+) & & 78 \\
\hline 5 & IBP $(+)$ plus & HLA-B27 $(+)$ plus & ESR/CRP $(-)$ & & 47 \\
\hline 5 & IBP (+) plus & HLA-B27 (+) plus & MRI (+) & & 93 \\
\hline 5 & IBP $(+)$ plus & HLA-B27 (+) plus & MRI (-) & & 14 \\
\hline 5 & IBP $(+)$ plus & Heel pain $(+)$ plus & HLA-B27 (+) plus & MRI (-) & 35 \\
\hline
\end{tabular}


Table 3 Sensitivity analysis

Pretest Prob. (\%) SpA features Post-test prob. (\%)

1 * $\begin{array}{ll}\mathbf{1}^{*} & \text { IBP (LR 3.1 } \\ \mathbf{2} & \text { IBP (LR 3.1 }\end{array}$

3 IBP (LR 3.1)

$4 \quad$ IBP (LR 3.1)

$5 \dagger \quad$ IBP (LR 3.1)

$7 \quad$ IBP (LR 3.1)

$10 \quad$ IBP (LR 3.1)

$5 \dagger \quad$ IBP (LR 3.1)

$5 \quad$ IBP (LR 3.1)

$5 \quad$ IBP (LR 3.1)

$3 \quad$ IBP (LR 3.1)

$7 \quad$ IBP (LR 3.1)

HLA-B27 (LR 9.0)
HLA-B27 (LR 9.0)
HLA-B27 (LR 9.0)
HLA-B27 (LR 9.0)
HLA-B27 (LR 9.0)
HLA-B27 (LR 9.0)
HLA-B27 (LR 9.0)
HLA-B27 (LR 9.0)
HLA-B27 (LR 9.0)
HLA-B27 (LR 9.0)
HLA-B27 (LR 9.0)
HLA-B27 (LR 9.0)

Uveitis (LR 7.3)†

Uveitis (LR 7.3)

Uveitis (LR 7.3)

Uveitis (LR 7.3)

Uveitis (LR 7.3)

Uveitis (LR 7.3)

Uveitis (LR 7.3)

Enthesitis (LR 3.4)†

Enthesitis (LR 2.5)

Enthesitis (LR 7.8)§

Enthesitis (LR 2.5)‡

The disease prevalence (pretest probability) and enthesitis were chosen as examples to illustrate effects of variation of these parameters on the post-test probability. A range of 1-10\% for the disease prevalence and the consecutive post-test probabilities are given using constant test features (presence of IBP, HLA-B27, and uveitis). Likewise, we chose different LRs (resulting from different sensitivities and specificities) of the test parameter "enthesitis" using either a disease prevalence of $5 \%$ (assumed to be representative throughout the study) or also other possible prevalences of $3 \%$ and $7 \%$, respectively.

${ }^{*}$ Figures in bold indicate figures that are varied in this sensitivity analysis (either for disease prevalence or for sensitivity and specificity of enthesitis). The resulting post-test probabilities are also shown in bold; tfigures assumed to be representative for either prevalence or $\mathrm{SpA}$ features which were taken for the calculations throughout the study; the LR of 2.5 results from a sensitivity of $25 \%$ and a specificity of $90 \%$ (see table 1; Boyer et $a^{P^{7}}$ ); ; the LR of 7.8 results from a sensitivity of $47 \%$ and a specificity of $94 \%$ (see table 1; CollantesEstevez et $a{ }^{p 8}$ ).

showed a limited sensitivity and specificity of about $50 \%$ for each when appropriate controls were used. ${ }^{45}{ }^{46}$ Because such figures do not change the disease probability, whether sacroiliitis on scintigraphy is present or absent, scintigraphy was not included in our calculations.
We did not include measures of spinal mobility tests such as Schober's test because low to moderate sensitivities or specificities, or both, were reported in previous studies.22 2534 Moreover, in patients with early axial SpA such figures can be expected to be even lower than in advanced disease..$^{103}$

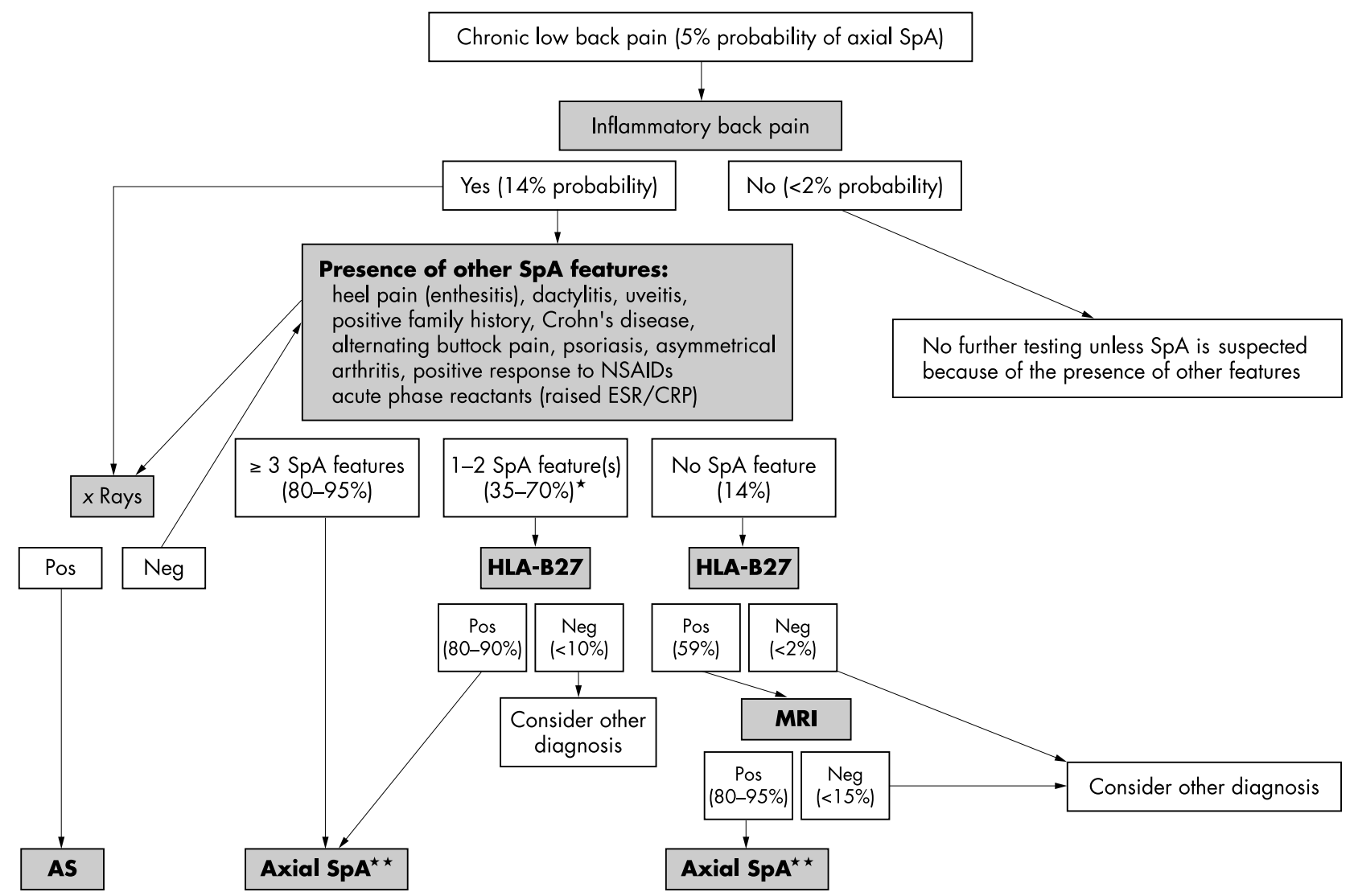

Figure 1 Decision tree on diagnosing axial SpA. Starting point is the presence or absence of inflammatory back pain (IBP) in patients presenting with chronic back pain. In general, for making the diagnosis of axial SpA a disease probability $>90 \%$ is suggested. *Dependent on which features are positive (table 2). ${ }^{*}$ If the probability of disease exceeds $90 \%$ we consider the diagnosis axial SpA as definite, if the probability is $80-90 \%$ we consider the diagnosis as probable (see also "Discussion"). 


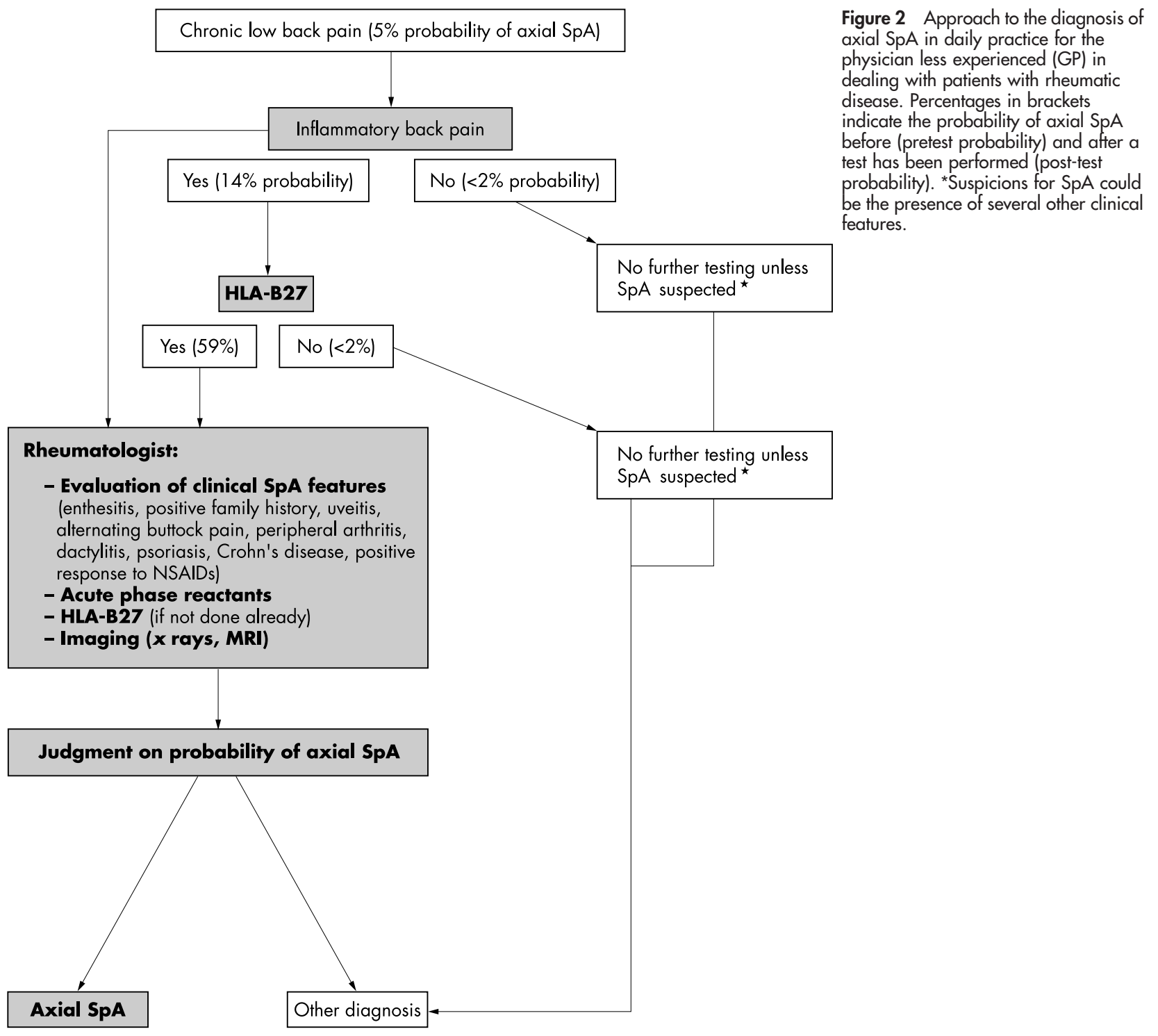

Pretest probability: prevalence of axial SpA among patients with low back pain

The starting point in our calculations was the prevalence of axial SpA (including AS and axial SpA without radiographic sacroiliitis) among patients with any kind of chronic LBPthat is, back pain of $>3$ months' duration. Among patients with chronic LBP the prevalence of AS was found to be $4.6 \%$ in one study, ${ }^{32}$ and in another study the prevalence of SpA (includes AS and USpA) was found to be 5\%. ${ }^{33}$ Therefore, a prevalence of $5 \%$ for axial $\mathrm{SpA}$ is assumed to be representative among patients with chronic LBP attending primary care.

Pretest probability, sensitivity, specificity, post-test probability, and likelihood ratios

The knowledge of the sensitivity and specificity of a diagnostic test in combination with the pretest probability-that is, the prevalence of the target disorder, allows calculation of the post-test probability of the target disorder after a positive or negative test. In the case of a positive test result the post-test probability of having the disease is equivalent to the positive predictive value. ${ }^{47-49}$

The post-test probability can be calculated by applying the following formula based on Bayes' theorem which is available at our website (http://www.rheumatologie-berlin. de/web/de/med_pre.htm). The probability of the presence of the disease in case of a positive test is:

$$
1+\left(\begin{array}{c}
\frac{100-\% \text { pretest probability of disease }}{\% \text { pretest probability of disease }} \\
\times \frac{100-\% \text { specificity }}{\% \text { sensitivity }}
\end{array}\right)
$$

and the probability of the presence of the disease in the case of a negative test is:

$$
1+\left(\begin{array}{c}
\frac{100-\% \text { pretest probability of disease }}{\% \text { pretest probability of disease }} \\
\times \frac{\% \text { specificity }}{100-\% \text { sensitivity }}
\end{array}\right)
$$

If a test is performed when the pretest probability is lowwhich is the case for axial SpA in general practice-this will hardly result in a high enough post-test probability and will therefore not suffice for making a diagnosis. Combining 
several tests, in that the post-test probability of the first test becomes the pretest probability of the subsequent test, can solve this problem. ${ }^{48} 49$ Accordingly, various tests have been combined in this study to assess the overall disease probability.

An LR expresses the odds that a given level of a diagnostic test result would be expected in a patient with (as opposed to someone without) the target disorder. ${ }^{49}$ LRs capture both sensitivity and specificity of a given test parameter in a single figure and may thus allow for better comparisons of diagnostic tests. Therefore, positive LRs are presented in table 1 in addition to sensitivity and specificity. LRs are defined as follows:

$$
\text { Positive LR }=(\text { sensitivity }) /(\text { l-specificity })
$$

if the parameter is present and

$$
\text { Negative LR }=(\text { l-sensitivity }) /(\text { specificity })
$$

if the parameter is absent.

\section{Incorporation of negative test results}

If negative test results are incorporated in the probability calculations they will usually decrease the disease probability. In a patient presenting with chronic back pain the following features if negative have been incorporated in the calculations: IBP, HLA-B27, response to NSAIDs, magnetic resonance imaging (MRI), and acute phase reactants. HLA-B27 testing gives a clear-cut yes/no answer with very few typing errors and is not subject to change. The absence of IBP, a lack of clinical response to NSAIDs, and a negative MRI should probably also be considered as truly negative test results and incorporated accordingly, although further studies to confirm the reported sensitivities and specificities are needed. For acute phase reactants there are no data on the consistency of findings in individual patients. Thus, negative findings should be incorporated with caution. Thus, in our opinion most clinical features should not be considered definitely negative in a given situation because they may turn positive in the future. Taking the family history may not be possible if family members are not available. Thus, negative assessments may be falsely negative. For these reasons we did not perform calculations for the latter features if they were negative.

\section{RESULTS}

Table 1 shows the study characteristics on which the calculations were based, and the sensitivities, specificities, and LRs of the various test parameters, together with the estimated average figure for each parameter. Table 2 shows examples of the resulting post-test probabilities, depending on the features present in a given patient. IBP has generally been accepted to be the leading symptom of the axial type of SpA and assessment of IBP was therefore used as the first diagnostic step. The probability of having axial SpA in a patient presenting to a physician because of symptoms suggesting IBP is only around 14\%, if we assume the background prevalence of axial SpA to be 5\%. To reach a high enough probability of axial SpA (that is, 90\%), additional findings are needed; these can be clinical features, laboratory tests, and skeletal imaging procedures typical of axial SpA (table 2). In general, a probability of at least $90 \%$ can be achieved if IBP plus two to three further features are present. The sequence of the tests applied does not affect the final disease probability and can therefore be adjusted according to the physician's preferences and/or experiences.

\section{Sensitivity analysis}

The post-test probability of having axial SpA depends on the pretest probability-that is, the prevalence of the disease. A prevalence of axial SpA of 5\% among patients with chronic back pain was assumed in our calculation because this figure appears to be representative based on available data. ${ }^{32}{ }^{33}$ To increase the pretest probability of $5 \%$ to a post-test probability of around $90 \%$ a combination of several features, such as IBP, acute anterior uveitis, and HLA-B27 positivity, for example, is required. If the disease prevalence were lower or higher than $5 \%$, then different post-test probabilities would emerge for the same features present. Table 3 shows examples for various prevalences of the disease and resulting post-test probabilities. Overall, the deviation of the resulting post-test probabilities was small if plausible figures for disease prevalence such as $2-3 \%$ or $7 \%$, respectively, were taken.

A sensitivity analysis can also be done for each SpA feature in that different sensitivities and specificities are assumed according to the reported variation of these figures in different studies. A more detailed analysis on all SpA parameters shown in table 1 can be done but would be beyond the scope of this article. One example of such analysis has been done for the feature heel pain (enthesitis) alone and in combination with the additional variation of the prevalence, the results of which are also presented in table 3.

\section{Diagnostic algorithm}

For daily clinical practice we suggest the following two diagnostic algorithms:

- For a physician experienced in taking care of patients with rheumatological problems, such as a rheumatologist, it seems logical that the assessment of IBP is going to result in the evaluation of other clinical features (fig 1), and this may be followed by HLA-B27 testing and skeletal imaging.

- For a physician less experienced in taking care of patients with rheumatological problems, such as a primary care physician or a general practitioner (GP), the clinically assessed presence of IBP ( $14 \%$ probability of axial SpA) can be followed by testing for HLA-B27. A positive test result would mandate a subsequent referral to a rheumatologist for further evaluation because the probability of axial SpA in such a patient has risen to 59\% (fig 2).

\section{DISCUSSION}

The primary aim of this study is to provide data on the probability of early axial SpA in patients with chronic back pain according to the absence or presence of certain clinical features, laboratory tests, or findings on skeletal imaging. The final post-test probability, which incorporates all relevant SpA features, may then help in confidently making the diagnosis of early axial SpA. The formula applied in this study is based on Bayes' theorem and allows calculation of the disease probability for any individual patient according to the clinical presentation. In general, the presence of IBP plus three further typical SpA features (table 2) results in a probability of about $90 \%$ for axial SpA. If a combination of SpA features with high LR such as acute anterior uveitis (LR 7.3), HLA-B27 (LR 9.0), or MRI (LR 9.0) is present, then the presence of IBP plus two such features may be sufficient to reach a probability of disease of $\geqslant 90 \%$. Such a high disease probability with an acceptable error rate should lend sufficient confidence for making the diagnosis of axial SpA. This is in accord with the generally accepted principles of decision analysis. ${ }^{49}$ If the probability is $80-89 \%$ we would consider the diagnosis of axial SpA as probable or highly probable. 
We chose IBP as the entry criterion for the assessment of patients with chronic back pain because IBP is the key symptom of axial involvement in SpA, and is present in the great majority of patients with AS and in about $70 \%$ of all patients with SpA. ${ }^{12} 1450$ If a patient with chronic LBP does not have IBP the probability of having axial SpA falls to less than $2 \%$. Unless other clinical features such as the presence or history of uveitis, enthesitis, or others strongly suggest the presence of SpA we do not recommend any further testing, including tests for HLA-B27, in such a patient because even a positive test result would not increase the probability of SpA to more than $13 \%$. Using the same methodological approach, we have recently proposed a diagnostic investigation for reactive arthritis, in which peripheral arthritis is the predominant symptom. ${ }^{51}$

The value of HLA-B27 as a diagnostic tool for early AS has been a subject of longstanding debate that has not yet been clarified. In several papers the advantages and disadvantages of HLA-B27 as a diagnostic test for AS/SpA have been discussed. $^{52-56}$ Some authors emphasised the great value of HLA-B27, ${ }^{17}{ }^{34}$ but it was generally felt that for a patient presenting with only chronic LBP the test would not be of much clinical value because the post-test probability after a positive HLA-B27 test would not exceed 30\% assuming a pretest probability of $5 \% .{ }^{54}$

The major difference between those earlier studies and our approach is that in the earlier studies HLA-B27 was considered as the only test in the probability calculations, whereas the concept of combining tests, ${ }^{48} 49$ as we have done, was not used. This is because the data on sensitivity and specificity for most of the clinical features that we have used for our analysis have only recently become available as a

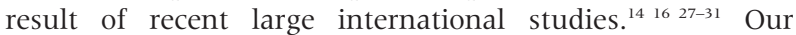
calculations show that HLA-B27 testing makes sense as long as it is used in combination with the relevant clinical, laboratory, or imaging parameters.

The outstanding value (in many but not all population groups) of HLA-B27 compared with other tests for diagnosing SpA is its high sensitivity and high specificity, which results in a high LR. Moreover, unlike the clinical criteria and imaging discussed here, HLA-B27 is neither dependent on the physician's experience nor on the patient's memory. HLAB27 testing is relatively cheap and reliable, it needs to be ordered only once, and it always gives a "yes" or "no" result. It is of note that HLA-B27 was the strongest single parameter in the distinction between SpA and non-SpA in the ESSG classification criteria. ${ }^{14}$

None the less, HLA-B27 was removed from the set of ESSG criteria because the ESSG criteria had to be applicable to populations in field studies without the need for a laboratory. We would like to point out that in non-white populations, who have either a high background prevalence of HLA-B27 in the general population (resulting in a lower specificity) or a less strong disease association (resulting in a lower sensitivity), the diagnostic value of HLA-B27 will be somewhat different. ${ }^{54} 57$

The sequence of tests applied in the diagnostic investigation in daily practice is determined by many factors, such as the physician's preference, clinical experience, and availability of the tests and their costs. In any case, in a search for axial SpA in a patient with back pain the presence or absence of IBP should be examined first. Many rheumatologists classify back pain as IBP if four of the following five features are present: $(a)$ age at onset $<40$ years; $(b)$ duration of back pain $>3$ months; $(c)$ insidious onset; $(d)$ morning stiffness; and (e) improvement with exercise. ${ }^{22}$ If IBP is present the experienced rheumatologist will assess other clinical features (family history, enthesitis of the heel, arthritis, dactylitis, uveitis, good response to NSAIDs, etc) at the initial visit before considering ordering pelvic $x$ ray examinations or tests such as erythrocyte sedimentation rate (ESR), $C$ reactive protein (CRP), or HLA-B27.

We suggest that the non-rheumatologist uses a different approach because most of the parameters listed in fig 1 are often not easy to assess in patients with chronic back pain: after making a diagnosis of IBP (based on appropriate criteria), such a physician may next order an HLA-B27 test. This physician should then refer the patient with a positive test result to a rheumatologist for further evaluation because at this stage the disease probability of axial SpA is about $60 \%$ (fig 2). Such a structured approach is likely to decrease rather than increase the overall costs because currently HLA-B27 testing, along with musculoskeletal imaging, is being ordered often inappropriately by primary care physicians. ${ }^{58}$ To apply this approach in primary care it will be an important task to teach the primary care physicians the characteristics of IBP. ${ }^{21} 22$ Acute phase reactants such as CRP and ESR are often used for the diagnostic investigation of inflammatory rheumatic diseases. However, their clinical use is somewhat limited for diagnosing axial SpA because of their moderate sensitivity (only about $50 \%$ ), although they do have some clinical value (with an estimated LR of 2.5)..$^{72}$ 34-36

As an alternative approach, the non-specialist might be advised to refer to the rheumatologist for further evaluation any patient with the clinical symptom of IBP, or any patient with chronic back pain with a positive HLA-B27 test. Choosing IBP alone would have the advantage that the non-specialist is not encouraged to misuse HLA-B27 testing. However, according to our calculations (post-test probability $14 \%$ ) the rheumatologist has to see about seven patients to make the diagnosis of axial SpA in one of them. Furthermore, it might not be easy for the non-specialist to assess IBP. The advantage of using HLA-B27 testing as the first and sole test in a patient with chronic LBP (post-test probability 33\%) is that no experience in the interpretation of clinical symptoms is necessary for the non-specialist. In this case the rheumatologist has to see three patients to make a diagnosis in one. At this moment we prefer the approach presented in fig 2 (combining assessment of IBP and HLA-B27 testing) before referral to the rheumatologist. Clearly, this issue is open to discussion and preferences will also depend on the local situation and availability.

Imaging is an important tool in the diagnostic investigation. If a pelvic radiograph shows definite sacroiliitis in a patient with IBP, this would be sufficient to classify the disease as AS. ${ }^{10}$ If, however, the radiograph is negative, the diagnosis of axial SpA can still be made if a high enough disease probability is reached based on the presence of other features. The appearance of radiological changes in the majority of patients with axial SpA is probably only a matter of time, but currently we do not know exactly the proportion of patients progressing to definite AS over time. In one study $60 \%$ of such patients had developed definite AS after 10 years of follow up. ${ }^{12}$ It took an average of 9 years $(+/-6$ years) for radiological sacroiliitis to appear in these patients with AS. ${ }^{12}$ A further $20 \%$ still had chronic uSpA and might have developed radiological sacroiliitis if their follow up had been continued for a longer time. It needs to be shown in future studies if radiologically detectable sacroiliitis should be regarded as a surrogate marker for severity, similar to the radiographic erosions in rheumatoid arthritis.

MRI is considered very helpful in detecting signs of sacroiliitis that are not yet visible on plain radiographs. However, special fat suppression techniques or application of gadolinium are necessary for acute inflammatory changes to be detectable on MRI with a high degree $(90-100 \%)$ of sensitivity and specificity. ${ }^{40-44}$ None the less, further MRI studies with appropriate techniques and including patients 
with non-inflammatory (mechanical or non-specific) back pain are warranted to confirm these data. In the absence of such data, we decided to choose rather conservative figures for sensitivity and specificity for our calculations. Moreover, as compared with clinical signs, such as acute anterior uveitis (diagnosed by an ophthalmologist) or an HLA-B27 test, MRI results may be ambiguous, particularly if the sacroiliitis is minor. The limited availability and high costs of MRI further hamper the widespread use of this technology. Therefore, in the diagnostic algorithm proposed herein the ordering of an MRI is the final diagnostic step. If the probability of axial SpA in a given patient with normal or equivocal radiograph of the sacroiliac joints does not exceed $50-70 \%$, a positive MRI scan enables one to make the diagnosis of axial SpA (probability of $\geqslant 90 \%$ ), whereas a normal finding on MRI may help to render the diagnosis as unlikely (probability 10-20\%).

In this study we used sensitivities and specificities from several studies conducted both in AS and the whole group of patients with SpA. We estimated average figures for each diagnostic test based on these studies, but we are well aware that applying different sensitivities and specificities may lead to different probabilities. To illustrate such an effect, we performed sensitivity analyses for the pretest probability by applying prevalence figures for axial SpA of as low as $2-3 \%$ and as high as $7 \%$, and also by applying various sensitivities and specificities for enthesitis as one example of the clinical parameters (table 3). The data show that the influence of this range of variation on the final disease probability is moderate to small. The serial application of the various tests assumes that the tests are independent. It is well recognised that often this is not the case. For example, a "positive family history" and "HLA-B27" may not be independent tests. This problem of "convergence" is usually clinically not important if no more than two to three diagnostic components are applied. ${ }^{49}$ To what extent any convergence will reduce the final posttest probability in the diagnostic investigation of suspected axial SpA cannot be deduced from the data presently available. However, we regard a considerably lower final post-test probability as unlikely. When these limitations are taken into account, the post-test probabilities given herein should be regarded as estimates and the validity of this diagnostic approach has to be confirmed in prospective clinical studies in which the expert's opinion might serve as the "gold standard".

Classification criteria do not have the medical standing for making a diagnosis, as discussed by Fries et al. ${ }^{59}$ Nevertheless, classification criteria are frequently used in daily clinical practice for diagnostic purposes. ${ }^{16}{ }^{60}$ In a patient with IBP, the fulfilment of the ESSG criteria for SpA classification requires the presence of only one further feature ${ }^{14}$; the probability of the presence of SpA in such a clinical setting ranges between 25 and $51 \%$ according to our calculations. For use in daily practice just meeting the ESSG criteria with a probability of not more than $51 \%$, however, is in our opinion not sufficient to make a diagnosis of axial SpA. This view is strongly supported by the Spanish study on patients with possible SpA. ${ }^{19}$

The Amor criteria, ${ }^{15}{ }^{16}$ like the ESSG criteria, ${ }^{14}$ are designed as multiple entry criteria which aim at encompassing the whole spectrum of SpA. In the Spanish follow up study $76.5 \%$ of those patients with possible SpA who had initially fulfilled the Amor criteria developed SpA (according to the expert opinion) compared with $46.6 \%$ of those who had initially fulfilled the ESSG criteria, ${ }^{19}$ indicating that the Amor criteria perform somewhat better than the ESSG criteria. The better performance of the Amor criteria can be easily explained by the data on disease probability presented herein because according to our calculations, similar to the Amor criteria, at least three to four features need to be present to make a definite diagnosis. In contrast with the Amor multiple entry criteria, a single entry criterion (IBP) is felt to be more helpful for a structured diagnostic approach in patients with LBP. Furthermore, MRI is not included in the Amor criteria because at the time the criteria were developed this technique had not yet been established in axial SpA.

In summary, we present a new approach to help clinicians diagnose axial SpA at an early stage in patients with IBP but without radiographic sacroiliitis. The decision trees proposed herein were developed by assessing the probabilities of the presence or absence of axial SpA in patients with chronic LBP, according to the presence or absence of the various clinical features, and also using the results of laboratory tests and skeletal imaging. We have shown that in the absence of definite radiological sacroiliitis at least two to three SpA features (clinical findings, laboratory tests, or skeletal imaging), in addition to the IBP as the starting point, are necessary to make a diagnosis of axial SpA with high degree of confidence. Testing for HLA-B27 among patients (of European descent) with IBP who do not show unequivocal radiological sacroiliitis can play a central part in the diagnostic investigation of axial SpA. Furthermore, for the first time, a role for MRI in such a diagnostic investigation has been analysed. A prospective study to confirm the clinical usefulness of this approach is in progress.

\section{ACKNOWLEDGEMENTS}

This study was supported by the BMBF (Kompetenznetz Rheuma), FKZ 01 GI9946.

\section{Authors' affiliations}

M Rudwaleit, J Sieper, Rheumatology, Department of Medicine I, Charité-Campus Benjamin Franklin, Berlin, Germany

D van der Heijde, Rheumatology, Research Institute Caphri, Maastricht University, The Netherlands

M A Khan, Case Western Reserve University, MetroHealth Medical Center, Cleveland, Ohio, USA

J Braun, Rheumazentrum Ruhrgebiet, Herne, Germany

\section{REFERENCES}

1 Deyo RA, Weinstein JN. Low back pain. N Engl J Med 2001;344:363-70.

2 Khan MA. Update on spondyloarthropathies. Ann Intern Med 2002;136:896-907.

3 Braun J, Bollow M, Remlinger G, Eggens U, Rudwaleit M, Distler A, et al. Prevalence of spondylarthropathies in HLA-B27 positive and negative blood donors. Arthritis Rheum 1998:41:58-67.

4 Saraux A, Guedes C, Allain J, Devauchelle V, Valls I, Lamour A, et al. Prevalence of rheumatoid arthritis and spondyloarthropathy in Brittany, France. Societe de Rhumatologie de l'Ouest. J Rheumatol 1999;26:2622-7.

5 Gran JT, Husby G, Hordvik M. Prevalence of ankylosing spondylitis in males and females in a young middle-aged population in Tromso, northern Norway. Ann Rheum Dis 1985;44:359-67.

6 Braun J, Sieper J, Breban M, Collantes-Estevez E, Davis J, Inman R, et al. Antitumour necrosis factor $\alpha$ therapy for ankylosing spondylitis: international experience. Ann Rheum Dis 2002:61/suppl III):iii 51-60.

7 Braun J, Brandt J, Listing J, Zink A, Alten R, Krause A, et al. Treatment of active ankylosing spondylitis with infliximab - a double-blind placebo controlled multicenter trial. Lancet 2002;359:1187-93.

8 Gorman JD, Sack KE, Davis JC. Treatment of ankylosing spondylitis by inhibition of tumor necrosis factor alpha. N Engl J Med 2002;346:1349-56.

9 Van den Bosch F, Kruithof E, Baeten D, Herssens A, de Keyser F, Mielants H, et al. Randomized double-blind comparison of chimeric monoclonal antibody to tumor necrosis factor alpha (infliximab) versus placebo in active spondylarthropathy. Arthritis Rheum 2002:46:755-65.

10 Van der Linden SM, Valkenburg HA, Cats A. Evaluation of the diagnostic criteria for ankylosing spondylitis. A proposal for modification of the New York criteria. Arthritis Rheum 1984;27:361-8.

11 Khan MA. Ankylosing spondylitis: introductory comments on its diagnosis and treatment. Ann Rheum Dis 2002;61(suppl III):iii3-7.

12 Mau W, Zeidler H, Mau R, Majewski A, Freyschmidt J, Stangel W, et al. Clinical features and prognosis of patients with possible ankylosing spondylitis. Results of a 10-year followup. J Rheumatol 1988;15:1109-14.

13 Feldtkeller E, Khan MA, van der Heijde D, van der Linden S, Braun J. Age at disease onset and diagnosis delay in HLA-B27 negative vs. positive patients with ankylosing spondylitis. Rheumatol Int 2003;23:61-6.

14 Dougados M, van der Linden S, Juhlin R, Huitfeldt B, Amor B, Calin A, et al. The European Spondylarthropathy Study Group preliminary criteria for the classification spondylarthropathy. Arthritis Rheum 1991;34:1218-27. 
15 Amor B, Dougados M, Miijiyawa M. Critères de classification des spondylarthropathies. Rev Rhum 1990;57:85-9.

16 Amor B, Dougados M, Listrat V, Menkes CJ, Roux H, Benhamou C, et al. Are classification criteria for spondylarthropathy useful as diagnostic criteria? Rev Rhum Engl Ed 1995:62:10-15.

17 Mau W, Zeidler H, Mau R, Majewski A, Freyschmidt J, Stangel W, et al. Evaluation of early diagnostic criteria for ankylosing spondylitis in a 10 year follow-up. Z Rheumatol 1990;49:82-7.

18 Dougados $\mathrm{M}$. Diagnostic features of ankylosing spondylitis. $\mathrm{Br} J$ Rheumatol 1995:34:301-5.

19 Collantes E, Veroz R, Escudero A, Munoz E, Munoz MC, Cisnal A, et al. Can some cases of 'possible' spondyloarthropathy be classified as 'definite' or 'undifferentiated' spondyloarthropathy? Value of criteria for

spondyloarthropathies. Spanish Spondyloarthropathy Study Group. Joint Bone Spine 2000;67:516-20.

20 Amor B. Usefulness of criteria for spondyloarthropathies. Joint Bone Spine 2000;67:502-3.

21 Rudwaleit M, Metter A, Listing J, Sieper J, Braun J. Clinical parameters in the differentiation of inflammatory back pain from non-inflammatory back pain [abstract]. Ann Rheum Dis 2002;61(suppl I):57.

22 Calin A, Porta J, Fries JF, Schurmann DJ. Clinical history as a screening test for ankylosing spondylitis. JAMA 1977;237:2613-14.

23 Goei The HS, Steven MM, van der Linden SM, Cats A. Evaluation of diagnostic criteria for ankylosing spondylitis: a comparison of the Rome, New York and modified New York criteria in patients with a positive clinical history screening test for ankylosing spondylitis. Br J Rheumatol 1985;24:242-9.

24 Van der Linden SM, Fahrer H. Occurrence of spinal pain syndromes in a group of apparently healthy and physically fit sportsmen (orienteers). Scand J Rheumatol 1988; 17:475-81.

25 Gran JT. An epidemiological survey of the signs and symptoms of ankylosing spondylitis. Clin Rheumatol 1985;4:161-9.

26 Amor B, Dougados M, Listrat V, Menkes CJ, Dubost JJ, Roux H, et al. Évaluation des critères des spondylarthropathies d'Amor et de l'European Spondylarthropathy Study Group (ESSG). Ann Med Interne 1991; 142:85-9.

27 Boyer GS, Templin DW, Goring WP. Evaluation of the European Spondylarthropathy Study Group preliminary classification criteria in Alaskan Eskimo populations. Arthritis Rheum 1993;36:534-8.

28 Collantes-Estevez E, Cisnal del Mazo A, Munoz-Gomariz E. Assessment of 2 systems of spondyloarthropathy diagnostic and classification criteria (Amor and ESSG) by a Spanish multicenter study. European Spondyloarthropathy Study Group. J Rheumatol 1995:22:246-51

29 Hukuda S, Minami M, Saito T, Mitsu H, Matsui N, Komatsubara Y, et al. Spondyloarthropathies in Japan: nationwide qeustionnaire survey performed by the Japan Ankylosing Spondylitis Society. J Rheumatol 2001;28:554-9.

30 Cury SE, Vilar MJ, Ciconelli RM, Ferraz MB, Atra E. Evaluation of the European Spondylarthropathy Study Group (ESSG) preliminary classification criteria in Brazilian patients. Clin Exp Rheumatol 1997;15:79-82.

31 Baddoura R, Awada H, Okais J, Habis T, Attoui S, Abi Saab M. Validation of the European Spondylarthropathy Study Group and B. Amor criteria for spondylarthropathies in Lebanon. Rev Rhum Engl Ed 1997;64:459-64.

32 Calin A, Kaye B, Sternberg M, Antell B, Chan M. The prevalence and nature of back pain in an industrial complex. A questionnaire and radiographic and HLA analysis. Spine 1980;5:201-5.

33 Underwood MR, Dawes P. Inflammatory back pain in primary care. Br J Rheumatol 1995:34:1074-7.

34 Sadowska-Wróblewska M, Filipowicz A, Garwolinska H, Michalski J, Rusiniak B, Wróblewska T. Clinical signs and symptoms useful in the early diagnosis of ankylosing spondylitis. Clin Rheumatol 1983;2:37-43.

35 Dougados M, Gueguen A, Nakache J-P, Velicitat P, Zeidler H, Veys E, et al. Clinical relevance of $\mathrm{C}$-reactive protein in axial involvement of ankylosing spondylitis. J Rheumatol 1999;26:971-4.

36 Spoorenberg A, van der Heijde D, de Klerk E, Dougados M, de Vlam K, Mielants $\mathrm{H}$, et al. Relative value of erythrocyte sedimentation rate and $\mathrm{C}$ reactive protein in assessment of disease activity in ankylosing spondylitis J Rheumatol 1999;26:980-4.

37 Schlosstein L, Terasaki PI, Bluestone R, Pearson CM. High association of an $\mathrm{HL}-\mathrm{A}$ antigen, W27, with ankylosing spondylitis. N Engl J Med 1973;288:704-6.
38 Brewerton DA, Hart FD, Nicholls A, Caffrey M, James DC, Sturrock RD. Ankylosing spondylitis and HL-A 27. The Lancet 1973;i:904-7.

39 Brophy S, Calin A. Ankylosing spondylitis: interaction between genes, joints, age at onset, and disease expression. J Rheumatol 2001;28:2283-8.

40 Braun J, Bollow M, Eggens U, Konig H, Distler A, Sieper J. Use of dynamic magnetic resonance imaging with fast imaging in the detection of early and advanced sacroiliitis in spondylarthropathy patients. Arthritis Rheum 1994;37:1039-45

41 Hanly JG, Mitchell MJ, Barnes DC, MacMillan L. Early recognition of sacroiliitis by magnetic resonance imaging and single photon emission computed tomography. J Rheumatol 1994;21:2088-95.

42 Bollow M, Braun J, Hamm B, Eggens U, Schilling A, Konig H, et al. Early sacroiliitis in patients with spondyloarthropathy: evaluation with dynamic gadolinium-enhanced MR imaging. Radiology 1995;194:529-36.

43 Blum U, Buitrago-Tellez C, Mundinger A, Krause T, Laubenberger J, Vaith P, et al. Magnetic resonance imaging (MRI) for detection of active sacroiliitis - a prospective study comparing conventional radiography, scintigraphy, and contrast enhanced MRI. J Rheumatol 1996;23:2107-15.

44 Puhakka KB, Jurik AG, Egund N, Schiottz-Christensen B Stengaard-Pedersen K, van Overeem Hansen $G$, et al. Imaging of sacroiliitis in early seronegative spondylarthropathy. Assessment of abnormalities by MR in comparison with radiography and CT. Acta Radiol 2003;44:218-29.

45 Miron SD, Khan MA, Wiesen EJ, Kushner I, Bellon EM. The value of quantitative sacroiliac scintigraphy in detection of sacroiliitis. Clin Rheumatol 1983;2:407-14.

46 Goei The HS, Lemmens AJ, Goedhard G, Lokkerbol H, Rahmy A, Steven MM et al. Radiological and scintigraphic findings in patients with a clinical history of chronic inflammatory back pain. Skeletal Radiol 1985;14:243-8.

47 Griner PF, Mayewski RJ, Mushlin Al, Greenland P. Selection and interpretation of diagnostic tests and procedures: principles and applications. Ann Intern Med 1981 ;94:553-600.

48 Pauker SG, Kassirer JP. Decision analysis. N Engl J Med 1987;316:250-8.

49 Sackett DL, Haynes RB, Guyatt GH, Tugwell P. Clinical epidemiology: a basic science for clinical medicine. 2nd ed. Boston, Toronto, London: Little, Brown, 1991:69-152.

50 Brandt J, Bollow M, Haberle J, Rudwaleit M, Eggens U, Distler A, et al. Studying patients with inflammatory back pain and arthritis of the lower limbs clinically and by magnetic resonance imaging: many, but not all patients with sacroiliitis have spondyloarthropathy. Rheumatology (oxford) 1999;38:831-6

51 Sieper J, Rudwaleit M, Braun J, van der Heijde D. Diagnosing reactive arthritis. Role of clinical setting in the value of serologic and microbiologic assays. Arthritis Rheum 2002:46:319-27.

52 Khan MA. Clinical application of HLA-B27 test in rheumatic diseases: a current perspective. Arch Intern Med 1980;140:177-80.

53 Hawkins BR, Dawkins RL, Christiansen FT, Zilko PJ. Use of the B27 test in the diagnosis of ankylosing spondylitis: a statistical evaluation. Arthritis Rheum 1981;24:743-6.

54 Khan MA, Khan MK. Diagnostic value of HLA-B27 testing ankylosing spondylitis and Reiter's syndrome. Ann Intern Med 1982:96:70-6.

55 Baron M, Zendel I. HLA-B27 testing in ankylosing spondylitis: an analysis of the pretesting assumptions. J Rheumatol 1989;16:631-4.

56 Gran JT, Husby G. HLA-B27 and spondyloarthropathy: value for early diagnosis? J Med Genet 1995;32:497-501.

57 Khan MA. HLA-B27 polymorphism and association with disease. J Rheumatol 2000;27:1110-14.

58 Gran JT, Nordvag BY. Referrals from general practice to an outpatient rheumatology clinic: disease spectrum and analysis of referral letters. Clin Rheumatol 2000;19:450.

59 Fries JF, Hochberg MC, Medsger TA, Hunder GG, Bombardier C. Criteria for rheumatic disease. Different types and different functions. The Amercian College of Rheumatology diagnostic and therapeutic criteria committee. Arthritis Rheum 1994;37:454-62.

60 Hunder GG. The use and misuse of classification and diagnostic criteria for complex diseases. Ann Intern Med 1998;129:417-18. 